\title{
Does social capital affect the incidence of functional disability in older Japanese? A prospective population-based cohort study
}

\section{Citation}

Aida, Jun, Katsunori Kondo, Ichiro Kawachi, S V Subramanian, Yukinobu Ichida, Hiroshi Hirai, Naoki Kondo, et al. 2012. "Does Social Capital Affect the Incidence of Functional Disability in Older Japanese? A Prospective Population-Based Cohort Study." Journal of Epidemiology and Community Health 67 (1): 42-47. https://doi.org/10.1136/jech-2011-200307.

\section{Permanent link}

http://nrs.harvard.edu/urn-3:HUL.InstRepos:41275601

\section{Terms of Use}

This article was downloaded from Harvard University's DASH repository, WARNING: This file should NOT have been available for downloading from Harvard University's DASH repository.

\section{Share Your Story}

The Harvard community has made this article openly available. Please share how this access benefits you. Submit a story.

Accessibility 


\title{
Does social capital affect the incidence of functional disability in older Japanese? A prospective population-based cohort study
}

\author{
Jun Aida, ${ }^{1,2}$ Katsunori Kondo, ${ }^{3}$ Ichiro Kawachi, ${ }^{4}$ S V Subramanian, ${ }^{4}$ Yukinobu Ichida, ${ }^{3}$ \\ Hiroshi Hirai, ${ }^{3,5}$ Naoki Kondo, ${ }^{6}$ Ken Osaka, ${ }^{1}$ Aubrey Sheiham, ${ }^{2}$ Georgios Tsakos, ${ }^{2}$ \\ Richard G Watt ${ }^{2}$
}

- Additional tables are published online only. To view these files please visit the journal online (http://dx.doi.org/ 10.1136/jech-2011-200307).

${ }^{1}$ Department of International and Community Oral Health, Tohoku University Graduate School of Dentistry, Sendai, Japan

${ }^{2}$ Department of Epidemiology and Public Health, University College London, London, UK

${ }^{3}$ Center for Well-being and Society, Nihon Fukushi

University, Nagoya, Japan

${ }^{4}$ Department of Society, Human Development and Health, Harvard School of Public Health, Boston, Massachusetts, USA ${ }^{5}$ Department of Civil Environmental Engineering, Iwate University, Iwate, Japan ${ }^{6}$ Department of Health Sciences, Interdisciplinary Graduate School of Medicine and Engineering, University of Yamanashi, Chuo-shi, Japan

\section{Correspondence to}

Dr Jun Aida, Department of International and Community Oral Health, Tohoku University Graduate School of Dentistry, 4-1, Seiryo-machi, Aoba-ku, Sendai, Miyagi 980-8575, Japan; j-aida@umin.ac.jp

Accepted 30 May 2012

Published Online First 3 July 2012

\begin{abstract}
Background Recent increases in numbers of older people have been accompanied by increases in those with functional disability. No study has examined the association between community social capital and the onset of functional disability.
\end{abstract}

Methods The association between community social capital and the onset of functional disability was examined using data from the Aichi Gerontological Evaluation Study, a prospective cohort established in 2003 in Japan. Perceptions of community social capital (indicators of social cohesion such as trust of others and extent of social participation) in 6953 men and 7636 women aged 65 years or older were surveyed. Multilevel survival analysis using the discrete-time hazard model was applied.

Results During 4-year follow-up, onset of functional disability occurred in 759 men and 1146 women. Women living in communities with higher mistrust had 1.68 (95\% Cl 1.14 to 2.49) times higher OR of onset of disability, even after adjusting for covariates. Mediators did not substantially change this association. Lack of social participation seemed to affect the health of women, though the effect was marginal (OR for covariates adjusted model $=1.12(95 \% \mathrm{Cl} 0.96$ to 1.31$))$. There were no significant ORs among men.

Conclusions Lower community social capital was associated with higher incidence of onset of functional disability among older women but not among men. Community-based interventions to promote social capital may be useful for preventing functional disability of older Japanese women.

\section{INTRODUCTION}

Functional disability, defined as difficulty performing activities of daily living, in ageing populations is a growing public health problem in many countries. ${ }^{1-4}$ Functional disability affects health status ${ }^{2}$ and also healthcare costs for longterm care. ${ }^{1}$ Japan has one of the highest proportions of older people in the world, with $22 \%$ of the population older than 65 years and $16 \%$ of such people reporting needs related to disabilities. ${ }^{5}$ The ageing of the population had strained budgets of the publicly funded long-term care insurance system, costs increased from US $\$ 35$ billion (1US $\$=100 ¥)$ in 2000 to US $\$ 65$ billion in 2008 . $^{3}$

There is a growing body of research showing that social capital is a determinant of a range of health outcomes, ${ }^{6-9}$ though previous studies of functional disability (ie, physical or cognitive disability) have mainly focused on individual risk factors, such as health status, lifestyle and social factors. ${ }^{10}$ Social capital was defined as 'features of social organisation, such as trust, norms and networks that can improve the efficiency of society by facilitating coordinated actions.' ${ }^{11}$ Although there have been concepts of individual-level social capital, ${ }^{12}$ applying community-level social capital in health research is important because it is possible that community-level social capital affects everyone in the community and it causes betweencommunity disparities of health outcomes.

In spite of rapid increases in the number of studies on social capital and health since $1997,{ }^{9}$ there were relatively few prospective cohort studies, and their results were not similar. ${ }^{7}$ For example, a 2-year follow-up Swedish study examined the relation between community social capital and onset of coronary heart disease. ${ }^{13}$ Their multilevel analysis showed protective effects of community social capital on disease onset, after adjusting for individual-level covariates. Another study showed that living in a community with the lowest level of social capital was associated with significantly higher mortality than living in one with the highest level of social capital in England. ${ }^{14}$ In contrast, community social capital was seemed detrimental to health among US adults diagnosed and hospitalised with serious illnesses. ${ }^{15}$ In New Zealand, there was a nonsignificant association between community social capital and mortality for men and women. ${ }^{16}$

To the best of our knowledge, no study has examined the association between community social capital and onset of functional disability. We considered social capital as a community-level resource and hypothesised that older people living in lower social capital community would be at higher risk of onset of functional disability, regardless of individual risk factors. In addition, we also hypothesised that the association of community social capital with onset of functional disability was attenuated by health behavioural and social support and network mediators. In the present study, we sought to examine prospectively the association between community social capital and onset of functional disability, using multilevel survival analysis.

\section{METHODS}

\section{Study population}

Data were from the Aichi Gerontological Evaluation Study (AGES), a prospective cohort established 
in 2003 in Japan by the Center for Well-being and Society of Nihon Fukushi University in Aichi. ${ }^{17-19}$ The study was in six municipalities that covered the entire southern part of the Chita peninsula in Aichi Prefecture, Japan. In 1 October 2003, there were 276208 people living in the six municipalities ( $N=113202$, 49724, $24337,22386,25753$ and 40806 , respectively), $18.0 \%$ of whom were 65 years or older. The average number of residents in the 44 districts in our analysis was thus around 6300. The sample was restricted to those 65 years or older and not receiving public long-term care insurance benefit because of physical or cognitive disability at baseline. From the municipalities, 29374 community-dwelling, aged 65 years or older, people were selected randomly. From this sample population, 14804 people responded to the baseline survey (response rate $=50.4 \%)$. Of the 14804 respondents, 91 were excluded due to death or functional decline or cognitive impairment prior to the 1 November 2003, while 45 could not be matched to health records via linkage. Of the 14668 respondents, 79 were excluded because they had missing key variables. Finally, 14589 subjects (6953 men and 7636 women) were included in the analysis. The AGES protocol was reviewed and approved by the ethics committee on Research of Human Subjects at Nihon Fukushi University.

\section{Follow-up}

The AGES Project focused on factors associated with health status, functional decline or cognitive impairment among noninstitutionalised older individuals in Japan. During 1-31 October 2003, baseline data were collected by a mailed questionnaire. The follow-up started in November 2003. Data about onset of functional disability until the end of follow-up (31 October 2007) were obtained from all six municipalities.

\section{Outcome variable}

The onset of functional (physical or cognitive) disability, defined as difficulty performing activities of daily living, was the primary outcome. Data on disability were collected from the public long-term care insurance database maintained by each municipality. Incidence of functional disability was determined using new registrations on the public long-term care insurance database..$^{20} \mathrm{~A}$ standardised multistep assessment of functional and cognitive impairment including a personal interview and examination by a physician was required for the long-term care requirement certification. ${ }^{21}$ For certification of disability, a computer-based evaluation of various criteria was used as well as reports of physician's examination. These criteria were used in previous epidemiological studies and form the basis of health needs assessment by local governments in Japan. ${ }^{22}$

\section{Social capital variables}

To measure community social capital, indicators of social cohesion, individual-level baseline data were aggregated for each of the 44 local districts. ${ }^{23}$ There are two distinct components of social capital: cognitive and structural. ${ }^{6}{ }^{12}$ In this study, both components were used. Responses to survey items about mistrust (cognitive social capital) and lack of social participation (structural social capital) were aggregated for each local district and used as our indicators of community social capital. Trust was a standard measure of cognitive social capital, ${ }^{6-8}$ assessed by the following question: 'Generally speaking, would you say that most people can be trusted?' Response alternatives were 'yes', 'depends' and 'no'. For analytical purposes, those who responded: 'yes' and 'depends' were grouped together, that is, trust was dichotomised into: 'yes/depends' versus 'no'. Social participation was our measure of structural social capital. ${ }^{12}$ Respondents were also asked whether they belonged to a hobby/ interest group (responses: 'yes' or 'no').

\section{Covariates and mediators}

We included established risk factors of functional status decline ${ }^{10}$ and supposed mediating factors between communitylevel social capital and health outcome $e^{24}$ as covariates or mediators. Questions on socio-demographic characteristics and baseline health status were included in the analyses as covariates: age, equivalised income, educational attainment, marital status, self-rated health, self-reported body mass index (BMI) and present illness. Lifestyle (smoking history, alcohol consumption and exercise) and individual social support and network were included as mediators between community-level social capital and individual health outcome. Five age categories were used (table 1). Household income and number of household members were recorded and then equivalised income was calculated to take into account household income and number of household members. Equivalised income was in US dollars (100 Japanese Yen = 1US\$) and divided into seven categories. Years of education was grouped into four groups. Marital status was categorised as married, separated/divorced and never married. Smoking history was collapsed in three categories and alcohol consumption into four categories. Subjects were asked how much they walked in minutes per day. Self-rated health was measured by a single question, "What is your current health status?: excellent, good, fair or poor'. BMI was categorised into four groups. Present illness was assessed by a question enquiring about current medical treatment for different conditions: cancer, heart disease, stroke, hypertension, diabetes, obesity, hyperlipidaemia, osteoporosis, arthritis, trauma, respiratory illnesses, gastrointestinal illnesses, liver disease, mental illness, visual/ hearing impairment, dysphagia, incontinence and others. Subjects were categorised as whether they had one or more current medical treatment illness. As covariates frequently had missing data, a 'missing' category was created for the analyses.

Individual social support, individual social network and community socio-demographic characteristics were adjusted in multivariable multilevel analysis. ${ }^{25}{ }^{26}$ Social support was measured by the following question, 'Do you have someone who looks after you when you are sick and stay in bed for a few days?: yes or no' Social network was measured by the question, 'How often do you see your friends?: almost everyday, several times a week, several times a month, several times a year, rarely or I have no friends'. To adjust for urbanisation, urbanisation based on population density in each municipality in 2000 was also included in the analyses.

\section{Statistical analysis}

The data included 14589 individuals (first level) nested in 44 local districts (second level). The median number of subjects in each local district was 265 (25th and 75th percentile, 183 and 412). The multilevel analysis framework assumes that individual health outcome is partly dependent on the districts where individuals live. Multilevel models estimate the variation of the outcome between districts (random effects) and the effects of community-level variables on the outcome, adjusting for individual compositional characteristics (fixed effects). ${ }^{27}$ Multilevel survival analysis, using discrete-time hazard model, was applied to calculate the OR and $95 \%$ CIs for functional disability during the follow-up period. ${ }^{28}$ ORs of social capital variables were estimated for a $10 \%$ change of the percentages of mistrust and lack of social participation in each community. To assess the 
Table 1 Descriptive characteristics of respondents

\begin{tabular}{|c|c|c|c|c|}
\hline & \multicolumn{2}{|l|}{ Men } & \multicolumn{2}{|l|}{ Women } \\
\hline & $\mathbf{N}(\%)$ & $\begin{array}{l}\text { Incidence rate per } \\
1000 \text { person-years } \\
(95 \% \mathrm{Cl})\end{array}$ & $\mathbf{N}(\%)$ & $\begin{array}{l}\text { Incidence rate per } \\
1000 \text { person-years } \\
(95 \% \mathrm{CI})\end{array}$ \\
\hline $65-69$ & $2558(36.8)$ & 10.1 (8.3 to 12.3$)$ & $2434(31.9)$ & $9.8(8.0$ to 12.0$)$ \\
\hline $70-74$ & $2127(30.6)$ & 20.5 (17.6 to 23.9$)$ & $2147(28.1)$ & $23.4(20.2$ to 26.9$)$ \\
\hline $75-79$ & $1406(20.2)$ & $43.7(38.3$ to 50.0$)$ & $1738(22.8)$ & $54.0(48.5$ to 60.1$)$ \\
\hline \multicolumn{5}{|l|}{ Education (years) } \\
\hline$<6$ & $176(2.5)$ & $71.1(52.4$ to 96.6$)$ & $491(6.4)$ & 103.9 (89.0 to 121.3 ) \\
\hline $6-9$ & $3600(51.8)$ & $34.2(31.1$ to 37.5$)$ & $4124(54.0)$ & 36.5 (33.6 to 39.7$)$ \\
\hline $10-12$ & $1806(26.0)$ & 22.7 (19.4 to 26.6$)$ & $2106(27.6)$ & 36.1 (32.1 to 40.6$)$ \\
\hline$\geq 13$ & $904(13.0)$ & 19.1 (15.0 to 24.4$)$ & $370(4.8)$ & $33.3(24.9$ to 44.6$)$ \\
\hline \multicolumn{5}{|l|}{ Equivalised income (\$) } \\
\hline $30000-39999$ & $1132(16.3)$ & 25.7 (21.3 to 31.1$)$ & $861(11.3)$ & 31.5 (25.9 to 38.4$)$ \\
\hline $40000-49999$ & $395(5.7)$ & $20.1(14.1$ to 28.8$)$ & $391(5.1)$ & $38.3(29.3$ to 49.9$)$ \\
\hline$\geq 50000$ & $286(4.1)$ & 21.5 (14.3 to 32.3$)$ & $241(3.2)$ & $40.9(29.4$ to 57.0$)$ \\
\hline \multicolumn{5}{|l|}{ Marital status } \\
\hline Married & $5732(82.4)$ & 26.2 (24.1 to 28.5$)$ & $3900(51.1)$ & 26.4 (23.9 to 29.2 ) \\
\hline Divorced & $650(9.3)$ & $58.9(49.6$ to 70.0$)$ & $2900(38.0)$ & $61.2(56.5$ to 66.3$)$ \\
\hline Never married & $43(0.6)$ & $19.4(6.3$ to 60.1$)$ & $202(2.6)$ & 48.1 (34.3 to 67.3$)$ \\
\hline \multicolumn{5}{|l|}{ Social network (frequency of meet one's friend) } \\
\hline Everyday & $1054(15.2)$ & $23.3(19.0$ to 28.6$)$ & $1679(22.0)$ & $33.0(28.8$ to 37.9$)$ \\
\hline Several times a week & $2455(35.3)$ & $22.3(19.5$ to 25.6$)$ & $3274(42.9)$ & 37.5 (34.2 to 41.1$)$ \\
\hline Several times a month & $1091(15.7)$ & 24.5 (20.1 to 29.8$)$ & $900(11.8)$ & $37.9(31.8$ to 45.2$)$ \\
\hline Good & $4280(61.6)$ & 21.5 (19.4 to 23.9$)$ & $4674(61.2)$ & 28.8 (26.4 to 31.5$)$ \\
\hline Poor & $1532(22.0)$ & $47.2(41.7$ to 53.5$)$ & $1742(22.8)$ & 64.1 (58.0 to 70.8$)$ \\
\hline Very poor & $372(5.4)$ & $97.1(79.9$ to 118.0$)$ & $387(5.1)$ & $132.9(113.3$ to 155.9$)$ \\
\hline \multicolumn{5}{|l|}{ Body mass index } \\
\hline$<18.5$ & $498(7.2)$ & $61.1(50.2$ to 74.4$)$ & $622(8.1)$ & 75.5 (64.5 to 88.3$)$ \\
\hline $18.5-24.9$ & $4775(68.7)$ & $27.0(24.7$ to 29.6$)$ & $4766(62.4)$ & 35.5 (32.8 to 38.4$)$ \\
\hline $25-29.9$ & $1277(18.4)$ & 22.5 (18.6 to 27.2 ) & $1504(19.7)$ & $29.7(25.5$ to 34.5$)$ \\
\hline$\geq 30$ & $83(1.2)$ & $29.4(15.3$ to 56.5$)$ & $166(2.2)$ & $47.8(33.2$ to 68.8$)$ \\
\hline \multicolumn{5}{|l|}{ Present illness } \\
\hline No & $2399(34.5)$ & $19.0(16.4$ to 22.1$)$ & $2205(28.9)$ & $27.7(24.3$ to 31.5$)$ \\
\hline Yes & $4166(59.9)$ & $36.4(33.4$ to 39.6$)$ & $4811(63.0)$ & 47.1 (44.0 to 50.5$)$ \\
\hline \multicolumn{5}{|l|}{ Alcohol consumption } \\
\hline Non & $3025(43.5)$ & 40.5 (36.8 to 44.5$)$ & $6429(84.2)$ & $42.6(40.1$ to 45.4$)$ \\
\hline Not drink everyday & $1222(17.6)$ & $24.6(20.4$ to 29.6$)$ & $643(8.4)$ & $22.1(16.9$ to 28.9$)$ \\
\hline Drink everyday ( $35 \mathrm{~g}$ of alcohol or less) & $1980(28.5)$ & 20.6 (17.6 to 24.1$)$ & $260(3.4)$ & $30.4(21.1$ to 43.8$)$ \\
\hline Drink everyday ( $\geq 35 \mathrm{~g}$ of alcohol) & $586(8.4)$ & $20.4(15.2$ to 27.3$)$ & $22(0.3)$ & $24.8(6.2$ to 99.2$)$ \\
\hline \multicolumn{5}{|l|}{ Smoking status } \\
\hline Non & $1902(27.4)$ & $32.8(28.8$ to 37.3$)$ & $6598(86.4)$ & 39.1 (36.7 to 41.7$)$ \\
\hline Ever & $3175(45.7)$ & 29.3 (26.3 to 32.6$)$ & $320(4.2)$ & 51.7 (39.9 to 66.8$)$ \\
\hline Current & $1570(22.6)$ & 27.3 (23.3 to 31.9 ) & $192(2.5)$ & 51.6 (37.1 to 71.9 ) \\
\hline \multicolumn{5}{|l|}{ Exercise } \\
\hline$<30$ min walk & 2289 (32.9) & 43.6 (39.3 to 48.5$)$ & 2464 (32.3) & 50.2 (45.7 to 55.2 ) \\
\hline $30-60$ min walk & 2314 (33.3) & $26.9(23.6$ to 30.6$)$ & $2255(29.5)$ & 37.6 (33.7 to 42.1$)$ \\
\hline $60-90$ min walk & $938(13.5)$ & 19.1 (15.0 to 24.2 ) & $841(11.0)$ & 33.5 (27.7 to 40.7$)$ \\
\hline
\end{tabular}


Table 1 Continued

\begin{tabular}{|c|c|c|c|c|}
\hline & \multicolumn{2}{|l|}{ Men } & \multicolumn{2}{|l|}{ Women } \\
\hline & $\mathbf{N}(\%)$ & $\begin{array}{l}\text { Incidence rate per } \\
1000 \text { person-years } \\
\text { (95\% CI) }\end{array}$ & $\mathbf{N}(\%)$ & $\begin{array}{l}\text { Incidence rate per } \\
1000 \text { person-years } \\
(95 \% \mathrm{Cl})\end{array}$ \\
\hline Urban & $2755(39.6)$ & 29.3 (26.1 to 32.9 ) & $2626(34.4)$ & 38.0 (34.3 to 42.1$)$ \\
\hline Semiurban & $2201(31.7)$ & 28.5 (25.1 to 32.5$)$ & 2506 (32.8) & 43.1 (39.0 to 47.6$)$ \\
\hline Rural & 1997 (28.7) & 33.1 (29.1 to 37.6$)$ & $2504(32.8)$ & 43.6 (39.5 to 48.1$)$ \\
\hline
\end{tabular}

hypothesis, we used the following models. At first, null model was used to assess whether onset of disability varied between districts or not. To estimate the proportion of the variation of the outcome between districts, intraclass correlation was calculated. Then, a social capital variable was included into the model to assess the univariate association between social capital variable and onset of disability. Mistrust and lack of social participation were separately included into the modes. Then, covariates were added into the models. To check the contribution of mediators on the relation between social capital and functional disability, mediators were added to the previous models. Because there were significant interactions between social capital variables and gender (results available from authors on request), we conducted stratified analyses by gender. Respondents who were lost to follow-up, by moving or death without onset disability, were included as censored data in the models.

Descriptive analyses were conducted using Stata V.11.1 (Stata Corp), and multilevel survival analyses were conducted using MLwiN 2.20 software package (Centre for Multilevel Modelling, University of Bristol, Bristol, UK).

\section{RESULTS}

During 4.0 years of follow-up for 6953 men, 759 (10.9\%) new cases of functional disability occurred. For 7636 women, 1146 $(15.0 \%)$ new cases of functional disability occurred.

Table 1 shows the descriptive characteristics of the respondents at baseline. Respondents with onset of functional disability were more likely to be older, have lower education, lower income, be divorced/never married, as well as report no social support, lower level of social network, worse self-rated health, lower BMI, having present illness, non-alcohol consumption, and lower exercise.

Table 2 shows the distribution of community social capital by gender. Women with onset of functional disability tended to live in communities with higher levels of mistrust and lack of social participation, at baseline.

Supplemental tables 3 and 4 show the results of multilevel survival analyses for men and women. There were significant variations on onset of functional disability between communities among both men and women; intraclass correlation among men and women were 3.4\% (Supplemental tables 3 and 4, null

Table 2 Distribution of community social capital

\begin{tabular}{lll}
\hline & $\begin{array}{l}\text { Rate of } \\
\text { mistrust (\%) } \\
\text { Mean (SD) }\end{array}$ & $\begin{array}{l}\text { Rate of non-social } \\
\text { participation (\%) } \\
\text { Mean (SD) }\end{array}$ \\
\hline $\begin{array}{lll}\text { Men } \\
\quad \text { Non-functional disability (N=6194) }\end{array}$ & $9.9(1.9)$ & $69.5(5.7)$ \\
$\quad \begin{array}{l}\text { Onset of functional disability (N=759) } \\
\text { Women }\end{array}$ & $9.9(2.0)$ & $69.7(6.0)$ \\
$\quad$ Non-functional disability (N=6490) & $10.0(1.9)$ & $69.7(6.0)$ \\
$\quad$ Onset of functional disability (N=1146) & $10.2(2.0)$ & $70.3(6.2)$ \\
\hline
\end{tabular}

models). Among men, there were no significant associations between onset of functional disability and social capital variables at baseline. In contrast, there were significant univariate associations between social capital variables at baseline and onset of functional disability for women (Supplemental table 4, models 1 and 4). Women in communities with higher mistrust (cognitive social capital) at baseline had 1.68 (95\% CI 1.14 to 2.49) times higher risk for onset of functional disability, even controlling for baseline health and social conditions (model 2). Mediators did not substantially explain this association $(\mathrm{OR}=$ 1.76 (95\% CI 1.20 to 2.60$)$ ) (model 3). Lack of social participation (structural social capital) seemed to affect women, though the effect was marginal (OR for covariates adjusted model = 1.12 (95\% CI 0.96 to 1.31 ) and OR for mediators adjusted model $=1.13$ (95\% CI 0.96 to 1.32 ) (models 5 and 6)).

\section{DISCUSSION}

To our knowledge, this is the first study to assess the association between onset of functional (physical or cognitive) disability and community social capital in a large sample of older community living adults. Among women, living in communities with lower social capital was prospectively associated with higher incidence of onset of functional disability within 4 years. Mediators did not substantially change these associations. There were no significant associations of social capital and disability among men.

Few studies examined community factors as a determinant of functional disability. Income inequality at the community level was associated with higher risk of functional disability. ${ }^{17} 29$ Erosion of social capital in more unequal societies is considered one mechanism for this association. ${ }^{9}$ However, no prospective study has examined the association between social capital and functional disability. A Finnish study using ecological and individual data showed that Swedish-speaking ethnic minority Finns had a longer active life than the Finnish-speaking Finns. $^{30}$ Although they did not examine the association between social capital and disability, the authors inferred that difference of social capital between groups was the cause. ${ }^{30} \mathrm{~A}$ cross-sectional study using only individual-level analysis showed that functional limitations among non-institutionalised persons aged 60 years and older were associated with individual trust. ${ }^{31}$ Our study partially supports the hypothesis that community social capital reduces the incidence of onset of disability among older women.

There are several plausible pathways linking social capital to health outcomes. ${ }^{24}$ First, social capital may affect individual health by influencing health-related behaviours through promotion of more rapid diffusion of health information or increasing the probability that healthy norms of behaviours are adopted and by exerting social control over health compromising behaviours. $^{32}$ Second, social capital may affect health by improving access to local service and amenities. Access to services, such as transportation, parks and recreation spaces, and 
community centres, could positively promote social participation among older people and thereby limit or delay the onset of disability. Third, community social capital may promote mental health by reducing psychological distress. ${ }^{33}$ Fourth, communities with higher social capital produce more egalitarian patterns of political participation resulting in implementation of policies ensuring the security of all their members. In our regression analysis, the addition of individual-level social support and social networks did not account for the association between community social capital and individual health. This suggests that any contextual influence of social capital on health is not mediated by differences in social support. Instead the association of social capital with health may mediated by community-level mechanisms such as collective efficacy, that is, the ability of a community to organise around the provision of services to the elderly that is independent of an individual's level of social integration.

In the present study, community social capital affected the onset of functional disability only among women. This pattern was consistent with previous cross-sectional studies investigated social environment such as social capital, ${ }^{34}$ socioeconomic deprivation, ${ }^{34} 35$ social fragmentation, ${ }^{36}$ or political and physical environment, ${ }^{35}$ and self-rated health ${ }^{34} 35$ and mental health. ${ }^{36}$ These studies showed that the association between women's health and social environmental factors was stronger than that for men. ${ }^{34-36}$ This pattern may reflect the fact that women spend more time at home than men ${ }^{34}$ and thus are more likely to have been more closely linked in with their communities, as well as influenced by their neighbourhood social context. A previous study in Japan supported these inferences. Japanese older women were more affected than men by healthcare resources of their community. ${ }^{37}$ These findings suggest that older women may benefit more than men from living in communities with higher levels of social capital.

The results of this study have public health implications. Among older women, 1SD (2\%) increase in community-level trust was associated with $10 \%$ reduction in the risk of incidence of onset of functional disability regardless of socio-demographic variables and health conditions.

This study has several limitations. First, it could be argued that the measurement of social capital used did not provide a full picture of social capital, though general trust and social participation were considered as one of the measurements of social capital. ${ }^{12} 25$ There is continuing debate about the definitions and measurement of social capital. ${ }^{26}$ Various types of social capital such as bonding, bridging and linking should be used. In addition, although general trust was widely used in previous studies, $^{6-8}$ there was a possibility that participants were not referring to their neighbours when they answered this question. Second, the measurements used were based on a self-administered questionnaire. As such, they are subject to response bias such as social desirability. ${ }^{38}$ Desirability bias may decrease the prevalence of lower social capital calculated from the responses to the questionnaire. Third, the $50.4 \%$ response rate to the survey may have reduced the generalisability of our findings. Respondents in this study tended to be younger than the typical older aged population in the survey municipalities. Nonrespondents also tended to have a higher prevalence of disability. ${ }^{39}$ Finally, the geographic scale we used in our analysis (districts) may be somewhat large for an analysis of 'community'-level social capital. The average population size per district $(N \approx 6300)$ is somewhat larger than the average population size of the US census tract $(N \approx 4000)$, which has been the standard definition of 'neighbourhood' employed in the US studies.

\section{What is already known on this subject}

Studies suggest a positive effect of social capital at community on health.

\section{What this study adds}

- No study has heretofore examined the associations between community social capital and functional disability.

- Among Japanese older women, but not among men, living in communities with lower social capital was prospectively associated with a higher incidence of onset of functional disability within 4 years, regardless of covariates.

- This study suggests that community social environment is an important factor in reducing onset of functional disability in older people.

The present study has some strengths. It had a relatively large sample size. We examined the influence of community contextual social capital after taking into account potential confounding and effects of mediators by individual compositional factors. ${ }^{26}$ Our measure of functional disability was not only obtained by self-report but based on physical examination prior to receiving long-term care insurance.

In conclusion, this prospective cohort study found that lower levels of community social capital was associated with higher incidence of onset of functional disability among older women but not among men. Social and behavioural mediators used in the present study did not substantially explain the associations. Interventions to reduce the onset of functional disability should address the community's social environment. Further studies are needed to determine how community social capital affects individual functional status.

Contributors JA had the idea for the study, participated in its design, performed the statistical analysis and drafted the manuscript as a principal author. KK helped develop the idea of the study, participated in acquiring the data and with design and edited the manuscript. IK participated in design of study and edited the manuscript. SVS participated in design of study, helped statistical analyses and critically revising the manuscript. $\mathrm{Yl}$ and $\mathrm{HH}$ participated in acquiring the data, helped statistical analyses and critically revising the manuscript. NK participated in designing study and critically revising the manuscript. KO helped with the data analysis and critically revised the manuscript. AS, GT and RGW participated in design of study and helped to write and revise the manuscript. All authors read and approved the final manuscript.

Funding This study was partially supported by a grant of Strategic Research Foundation Grant-aided Project for Private Universities from Ministry of Education, Culture, Sports, Science and Technology, Japan, 2009-2013, and Grant-in-Aid for Scientific Research (B) (22390400) and (C) (22592327) from the Japan Society for the Promotion of Science. The sponsors of the study had no role in the study design, data collection, data analysis, data interpretation or writing of the paper.

\section{Competing interests None.}

Ethics approval The ethics approval was provided by the ethics committee on Research of Human Subjects at Nihon Fukushi University.

Provenance and peer review Not commissioned; externally peer reviewed.

\section{REFERENCES}

1. Fried TR, Bradley EH, Williams CS, et al. Functional disability and health care expenditures for older persons. Arch Intern Med 2001;161:2602-7. 
2. Keeler $\mathbf{E}$, Guralnik JM, Tian $\mathrm{H}$, et al. The impact of functional status on life expectancy in older persons. J Gerontol A Biol Sci Med Sci 2010;65:727-33.

3. Ministry of Health, Labour and Welfare. Kaigo hoken jigyo jyokyo hokoku. Tokyo, Japan: Ministry of Health, Labour and Welfare, 2010.

4. Griffith L, Raina $\mathrm{P}, \mathrm{Wu} \mathrm{H}$, et al. Population attributable risk for functional disability associated with chronic conditions in Canadian older adults. Age Ageing 2010:39:738-45.

5. Cabinet Office Japan. White Paper on the Aging Society. 2010. http://www8.cao. go.jp/kourei/whitepaper/index-w.html (accessed 16 Jun 2012).

6. Islam MK, Merlo J, Kawachi I, et al. Social capital and health: does egalitarianism matter? A literature review. Int J Equity Health 2006;5:3.

7. Kim D, Subramanian SV, Kawachi I. Social Capital and Physical Health. In: Kawachi I, Subramanian SV, Kim D, eds. Social capital and health. New York: Springer, 2008:139-90.

8. De Silva MJ, McKenzie K, Harpham T, et al. Social capital and mental illness: a systematic review. J Epidemiol Community Health 2005;59:619-27.

9. Kawachi I, Kennedy BP, Lochner K, et al. Social capital, income inequality, and mortality. Am J Public Health 1997:87:1491-8.

10. Stuck AE, Walthert JM, Nikolaus T, et al. Risk factors for functional status decline in community-living elderly people: a systematic literature review. Soc Sci Med 1999:48:445-69.

11. Putnam RD. Making Democracy Work: Civic Traditions in Modern Italy. Princeton: Princeton Univ Press, 1993.

12. Baum FE, Ziersch AM. Social capital. J Epidemiol Community Health 2003:57:320-3.

13. Sundquist J, Johansson SE, Yang M, et al. Low linking social capital as a predictor of coronary heart disease in Sweden: a cohort study of 2.8 million people. Soc Sci Med 2006;62:954-63

14. Mohan J, Twigg L, Barnard S, et al. Social capital, geography and health: a smallarea analysis for England. Soc Sci Med 2005;60:1267-83.

15. Wen M, Cagney KA, Christakis NA. Effect of specific aspects of community social environment on the mortality of individuals diagnosed with serious illness. Soc Sci Med 2005;61:1119-34.

16. Blakely T, Atkinson J, Ivory V, et al. No association of neighbourhood volunteerism with mortality in New Zealand: a national multilevel cohort study. Int J Epidemiol 2006; $35: 981-9$

17. Kondo N, Kawachi I, Hirai $\mathrm{H}$, et al. Relative deprivation and incident functional disability among older Japanese women and men: prospective cohort study. J Epidemiol Community Health 2009;63:461-7.

18. Nishi A, Kondo K, Hirai H, et al. Cohort profile: the ages 2003 cohort study in Aichi, Japan. J Epidemiol 2011:21:151-7.

19. Kondo K, ed. Health Inequalities in Japan: An Empirical Study of the Older People. Melbourne: Trans Pacific Press, 2010

20. Matsuda S, Yamamoto M. Long-term care insurance and integrated care for the aged in Japan. Int J Integr Care 2001;1:e28.

21. Ministry of Health, Labour and Welfare. Long-Term Care Insurance in Japan. 2008. http://www.mhlw.go.jp/english/topics/elderly/care/index.html laccessed 16 Jun 2012).
22. Kondo N, Kazama M, Suzuki K, et al. Impact of mental health on daily living activities of Japanese elderly. Prev Med 2008;46:457-62.

23. Blakely T, Subramanian SV. Multilevel studies. In: Oakes JM, Kaufman JS, eds. Methods in Social Epidemiology. San Francisco: Jossey-Bass, 2006:316b-40b.

24. Kawachi I, Berkman L. Social cohesion, social capital, and health. In: Berkman L, Kawachi I, eds. Social Epidemiology. New York: Oxford University Press, 2000:174-90.

25. Harpham T, Grant E, Thomas E. Measuring social capital within health surveys: key issues. Health Policy Plan 2002:17:106-11.

26. Kawachi I, Subramanian SV, Kim D. Social capital and health: a decade of progress and beyond. In: Kawachi I, Subramanian SV, Kim D, eds. Social Capital and Health. New York: Springer, 2008:1-26.

27. Leyland A, Goldstein H, eds. Multilevel Modelling of Health Statistics. New York: Wiley, 2001.

28. Subramanian SV, Elwert F, Christakis N. Widowhood and mortality among the elderly: the modifying role of neighborhood concentration of widowed individuals. Soc Sci Med 2008:66:873-84.

29. Alves LC, Leite Ida C, Machado CJ. Factors associated with functional disability of elderly in Brazil: a multilevel analysis. Rev Saude Publica 2010;44:468-78.

30. Hyyppa MT, Maki J. Why do Swedish-speaking Finns have longer active life? An area for social capital research. Health Promot Int 2001;16:55-64.

31. Pollack CE, von dem Knesebeck 0 . Social capital and health among the aged: comparisons between the United States and Germany. Health Place 2004; 10:383-91.

32. Ueshima K, Fujiwara T, Takao $\mathrm{S}$, et al. Does social capital promote physical activity? A population-based study in Japan. PLoS One 2010;5:e12135.

33. Phongsavan P, Chey T, Bauman A, et al. Social capital, socio-economic status and psychological distress among Australian adults. Soc Sci Med 2006;63:2546-61.

34. Kavanagh AM, Bentley R, Turrell G, et al. Does gender modify associations between self rated health and the social and economic characteristics of local environments? $J$ Epidemiol Community Health 2006;60:490-5.

35. Stafford M, Cummins S, Macintyre S, et al. Gender differences in the associations between health and neighbourhood environment. Soc Sci Med 2005; 60:1681-92.

36. Ivory VC, Collings SC, Blakely T, et al. When does neighbourhood matter? Multileve relationships between neighbourhood social fragmentation and mental health. Soc Sci Med 2011;72:1993-2002.

37. Hanibuchi T, Aida J, Nakade M, et al. Geographical accessibility to dental care in the Japanese elderly. Community Dent Health 2011;28:128-35.

38. Hebert JR, Clemow L, Pbert L, et al. Social desirability bias in dietary self-report may compromise the validity of dietary intake measures. Int $\mathrm{J}$ Epidemiol 1995;24:389-98

39. Hoeymans N, Feskens EJ, Van Den Bos GA, et al. Non-response bias in a study of cardiovascular diseases, functional status and self-rated health among elderly men. Age Ageing 1998;27:35-40. 